\title{
Effect of Market Orientation, Marketing Capability, Product Innovation on Performance
}

\section{Introduction}

Ketika Indonesia mengalami krisis ekonomi, keadaan ini berdampak pada perusahaan-perusahaan besar, dan banyak perusahaan yang bangkrut atau bahkan bangkrut. Kasus lainnya adalah usaha kecil dan menengah dapat bertahan karena tidak menggunakan bahan baku impor dalam jumlah besar, melainkan menjadi penyelamat dampak krisis ekonomi (Andalan \& Hikmah, 2013). Dibandingkan dengan perusahaan besar, usaha mikro dan kecil pulih lebih cepat dari krisis, dan pekerja yang terkena PHK dari perusahaan besar diserap ke dalam usaha mikro dan kecil ini. Cepat pulihnya usaha kecil dan mikro terutama disebabkan oleh sifat usaha yang relatif fleksibel, modal yang relatif kecil, dan umumnya tidak tergantung pada bahan baku impor dan utang luar negeri. Bangkrutnya kelompok usaha Indonesia dan ketangguhan usaha kecil dan mikro dalam menghadapi krisis ekonomi telah melahirkan banyak usaha kecil dan mikro baru (Smecda, 2010). Peran UKM dalam pembangunan ekonomi sangat penting, terutama dalam menyediakan lapangan kerja dan sumber pendapatan bagi kelompok berpenghasilan rendah. Data Choiri (2018) menunjukkan bahwa pada tahun 2017, usaha mikro dan kecil (UMK) memberikan kontribusi signifikan terhadap produk domestik bruto (PDB) Indonesia, mencapai 60,34\%. Selain itu, usaha mikro dan kecil (UMK) juga terbukti menjadi penyerap tenaga kerja yang paling efektif, yaitu sekitar 97,22\% pada tahun 2017 . Oleh karena itu, usaha mikro dan kecil sangat berpengaruh dalam perekonomian Indonesia. Menurut studi tahun 2015 oleh Lembaga Pengembangan Perbankan Indonesia (LPPI) dan Bank Indonesia (BI), salah satu faktor yang mempengaruhi kinerja usaha mikro dan kecil (UMK) adalah kemampuan menginterpretasikan permintaan pasar yang kurang tajam. Untuk mencapai tujuan tersebut, perusahaan harus mampu merumuskan strategi yang berorientasi pasar sehingga usaha kecil dan mikro dapat meningkatkan kinerja usahanya dengan baik.

\section{The Scope of Research}

Penelitian ini berfokus pada UMK di wilayah Jakarta Barat. Adapun pertimbangan penulis meneliti UMK di Jakarta Barat karena menurut sensus ekonomi yang dilakukan oleh Badan Pusat Statistik (BPS) tahun 2016 bahwa Jakarta Barat sebagai salah satu kota administratif di Provinsi DKI Jakarta yang merupakan kota dengan jumlah penduduk terbanyak. unit UMK di Jakarta yaitu 306.129 dari total 322.049 usaha atau $26,51 \%$ dari total usaha mikro kecil di Jakarta (lihat tabel 1). Jumlah yang 
besar ini menunjukkan bahwa Jakarta Barat memiliki potensi ekonomi yang lebih besar dibandingkan dengan daerah lain di DKI Jakarta.

\section{Research Purpose}

Penelitian ini bertujuan untuk menganalisis pengaruh orientasi pasar terhadap kinerja UMK di Jakarta Barat; menganalisis pengaruh kapabilitas pemasaran terhadap kinerja UMK di Jakarta Barat; menganalisis pengaruh inovasi produk terhadap kinerja UMK di Jakarta Barat; serta menganalisis pengaruh orientasi pasar, kapabilitas pemasaran, dan inovasi produk secara simultan terhadap kinerja UMK di Jakarta Barat.

Tinjauan Literatur

LPPI; Bank Indonesia; Bank Dunia (2015) mengklasifikasikan kriteria usaha mikro, kecil, menengah dan besar menurut jumlah karyawan, aset dan omset sebagai berikut :

Table 3: Classification of Micro, Small, Medium and Large Business

\begin{tabular}{|l|l|l|l|}
\hline Business Scale & Criteria & Turnover & $\begin{array}{l}\text { Number } \\
\text { employees }\end{array}$ \\
\cline { 2 - 4 } & Asset of \\
\hline Micro & $<50$ million & $<300$ million & 10 \\
\hline Small & $\begin{array}{l}>50 \text { million }-500 \\
\text { million }\end{array}$ & $\begin{array}{l}>300 \text { million }-2,5 \\
\text { million }\end{array}$ & 30 \\
\hline Medium & $\begin{array}{l}>500 \text { million }-10 \\
\text { billion }\end{array}$ & 2,5 million -50 billion & $<300$ \\
\hline Large & $>10$ billion & $>50$ billion & $>300$ \\
\hline
\end{tabular}

Source: LPPI; Bank Indonesia; The World Bank (2015)

\section{Business Performance}

Performa bisnis Kinerja merupakan hasil evaluasi dari pekerjaan yang telah dilakukan dibandingkan dengan kriteria yang telah ditetapkan bersama (Robbins dalam Rai, 2008). Di sisi lain, Ahuya menjelaskan bahwa kinerja adalah suatu proses atau cara kerja yang dilakukan oleh individu atau kelompok dalam organisasi (Rai, 2008). Kinerja merupakan hal penting yang harus dicapai oleh setiap perusahaan karena kinerja merupakan cerminan dari kemampuan perusahaan dalam mengelola dan mengalokasikan sumber dayanya. 


\section{Market Orientation}

Menurut Mauzano dalam Sugiyarti (2016), menjelaskan orientasi pasar adalah fokus perencanaan strategis unit bisnis dalam memenuhi beberapa tuntutan berupa semua fungsi dalam bisnis dan mampu menyerap semua informasi penting yang mempengaruhi pembelian, interfungsi dan pengambilan keputusan divisi, dan divisi sebagai fungsi koordinasi yang baik dan memiliki komitmen dalam melaksanakan kegiatan pemasaran. Best (2009) mengemukakan bahwa untuk mencapai orientasi pasar yang kuat, sebuah bisnis perlu mengadopsi filosofi manajemen berbasis pasar.

\section{Marketing Capability}

Kotler dan Keller (2009) mendefinisikan kapabilitas pemasaran sebagai fungsi organisasi dan serangkaian proses untuk menciptakan, mengomunikasikan, dan memberikan nilai kepada pelanggan dan mengelola hubungan pelanggan. Tujuan kapabilitas pemasaran menurut Hasan (2013) antara lain memaksimalkan keuntungan, memaksimalkan pangsa pasar, memaksimalkan penjualan, meningkatkan citra merek, meningkatkan kepuasan pelanggan, memberikan nilai dan menjaga stabilitas orientasi pasar. Pengertian kapabilitas pemasaran menurut Saladin (2003) adalah suatu sistem total kegiatan bisnis yang dirancang untuk merencanakan, menentukan orientasi pasar, mempromosikan dan mendistribusikan barang yang dapat memuaskan keinginan dan mencapai pasar sasaran dan tujuan perusahaan. Menurut Gáti (2015), ada beberapa dimensi kegiatan pemasaran seperti alat pemasaran klasik, orientasi kewirausahaan, kemampuan beradaptasi, pentingnya pemasaran, keterampilan komunikasi pemasaran, orientasi pasar, kinerja pemasaran, dan kinerja perusahaan.

\section{Product Innovation}

Inovasi produk adalah kunci keberhasilan organisasi, peningkatan pangsa pasar dan kinerja bisnis (Hassan et al., 2013). Hal ini juga didukung oleh teori Kotabe dalam Tamamudin (2012) yang menunjukkan bahwa semakin tinggi inovasi produk yang dilakukan perusahaan akan meningkatkan kinerja perusahaan melalui keputusan pembelian yang semakin meningkat.

\section{Research Framework}

Kerangka penelitian ini sebagai berikut : 
Figure 1. Research Framework

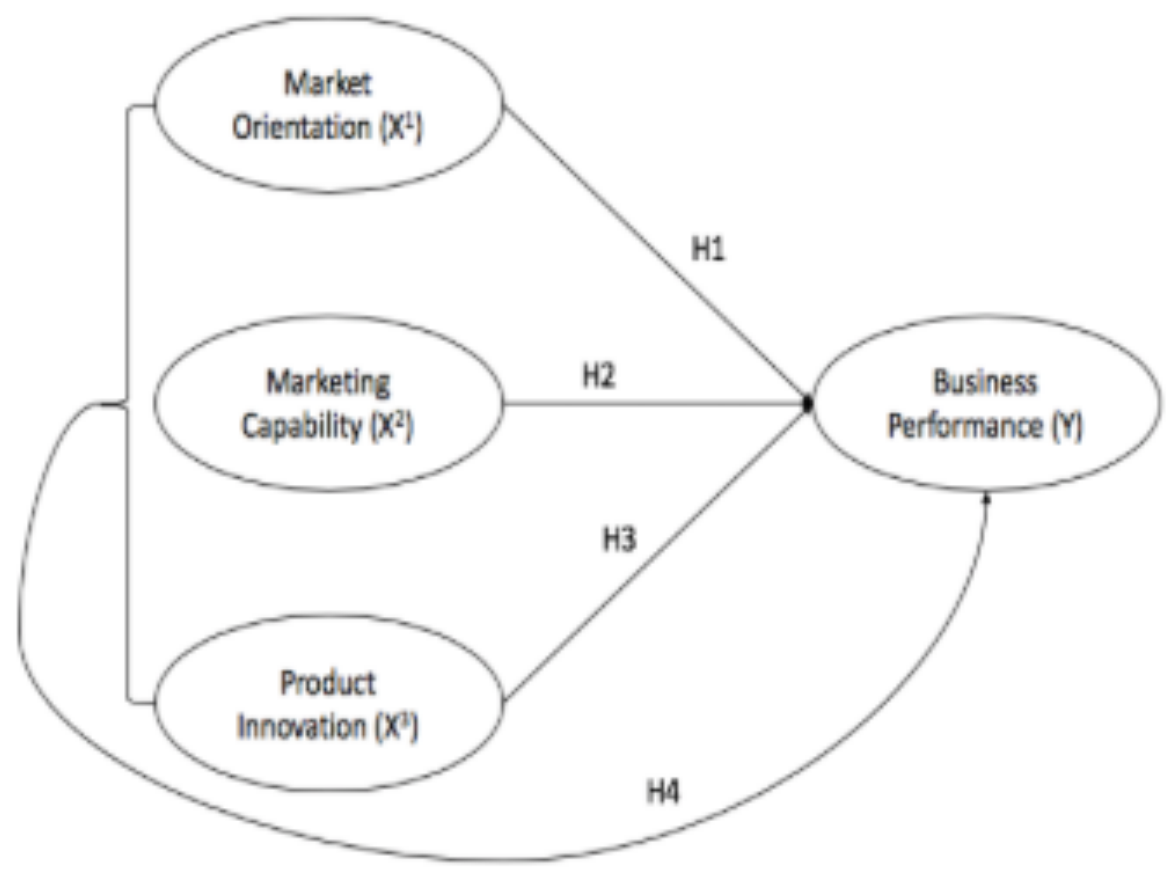

Source: Authors (2019)

Hypothesis 1, market orientation relationship to business performance Ho: market orientation does not affect business performance $\mathrm{Ha}$ : market orientation has an effect on business performance

Hypothesis 2, marketing capability relationship to business performance Ho: marketing capability does not affect business performance $\mathrm{Ha}$ : the marketing capability has an effect on business performance Hypothesis 3, product innovation relationship to business performance Ho : product innovation does not affect business performance $\mathrm{Ha}$ : product innovation has an effect on business performance Hypothesis 4 , market orientation, marketing capability and product innovation relationship to business performance

Ho: market orientation, marketing capability and product innovation does not affect business performance

$\mathrm{Ha}$ : market orientation, marketing capability and product innovation has an effect on business performance 


\section{Method}

Penelitian kuantitatif adalah metode penelitian yang didasarkan pada filosofi positivisme, digunakan untuk meneliti populasi atau sampel tertentu, mengumpulkan data dengan menggunakan instrumen penelitian, menganalisis data kuantitatif atau statistik untuk menguji hipotesis yang telah ditetapkan (Sugiyono, 2017). Penelitian ini menggunakan pendekatan kuantitatif karena penelitian ini bertujuan untuk menguji hipotesis sebagai jawaban sementara penelitian dengan menganalisis data menggunakan statistik. Penelitian ini merupakan penelitian one-shot dan penelitian cross sectional. Studi potong lintang adalah penelitian yang dapat dilakukan dengan mengumpulkan data satu kali, melalui jangka waktu beberapa hari atau beberapa minggu atau beberapa bulan untuk menjawab pertanyaan dalam penelitian (Sekaran dan Bougie, 2013). Sedangkan pengumpulan data menggunakan kuesioner menggunakan skala 5 Likert.

\section{Results and Discussion}

Berdasarkan hasil pengisian kuesioner diperoleh profil responden:

A. Berdasarkan tempat tinggal.100\% responden yang berdomisili di Jakarta Barat

B. Berdasarkan jenis barangnya. 50\% responden menjual produk makanan dan minuman, $26 \%$ dari responden menjual pakaian, 11\% responden menjual kosmetik, 1\% elektronik, $1 \%$ tekstil, 1\% aksesoris dan 10\% lainnya

C. Berdasarkan pendidikan. 44\% SMA, 6\% diploma, 45\% sarjana dan 5\% gelar master

D. Berdasarkan jenis badan usaha. $80 \%$ adalah perusahaan dagang, $4 \%$ adalah perseroan terbatas, $8 \%$ adalah persekutuan komanditer, $4 \%$ adalah firma, $2 \%$ adalah yayasan dan $2 \%$ lainnya

E. Berdasarkan jenis kelamin. 59\% laki-laki dan $41 \%$ perempuan

F. Berdasarkan usia responden. 28\% berusia di bawah 25 tahun, 26\% berusia 26-35 tahun, 34\% berusia 36-

45 tahun dan $12 \%$ berusia $46-55$ tahun

G. Berdasarkan usia bisnis. 46\% responden yang usia usahanya antara 2-3 tahun, 36\%

responden yang umur usaha kurang dari 1 tahun, 8\% umur usaha 4-5 tahun, 5\% umur usaha 5-6 tahun, 5\% umur usaha sama atau lebih dari 7 tahun. 
H. Berdasarkan jumlah karyawannya. 49\% di bawah 3, 23\% memiliki 4-6 karyawan, 12\% memiliki 7-9 karyawan, 5\% memiliki 10-13 karyawan, 11\% di atas 14 karyawan

Saya. Berdasarkan pasar. $85 \%$ nasional, $15 \%$ nasional dan internasional.

\section{Conclusion}

Penelitian ini bertujuan untuk menganalisis hubungan orientasi pasar, kapabilitas pemasaran, dan inovasi produk terhadap kinerja usaha UMK di Jakarta Barat. Kesimpulan yang diperoleh dari hasil analisis data menunjukkan bahwa variabel orientasi pasar, kapabilitas pemasaran, dan inovasi produk secara parsial berpengaruh terhadap kinerja UMK di Jakarta Barat; bahwa variabel orientasi pasar, kapabilitas pemasaran, dan inovasi produk secara simultan berpengaruh terhadap kinerja UMK di Jakarta Barat; bahwa variabel yang paling signifikan pengaruhnya adalah variabel inovasi produk diikuti oleh variabel kapabilitas pemasaran dan terakhir variabel orientasi pasar. 